\title{
Interview with Joseph Margolis
}

Joseph Margolis

\section{(2) OpenEdition}

\section{Journals}

Electronic version

URL: http://journals.openedition.org/ejpap/301

DOI: 10.4000/ejpap.301

ISSN: 2036-4091

\section{Publisher}

Associazione Pragma

\section{Electronic reference}

Joseph Margolis, «Interview with Joseph Margolis », European Journal of Pragmatism and American Philosophy [Online], VI-2 | 2014, Online since 24 December 2014, connection on 14 September 2020 URL : http://journals.openedition.org/ejpap/301

\section{(c) (i) () $\Theta$}

Author retains copyright and grants the European Journal of Pragmatism and American Philosophy right of first publication with the work simultaneously licensed under a Creative Commons AttributionNonCommercial-NoDerivatives 4.0 International License. 


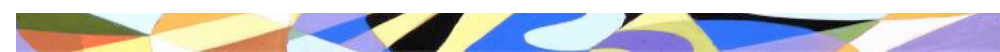

EUROPEAN JOURNAL OF PRAGMATISM AND AMERICAN PHILOSOPHY

COPYRIGHT C 2009 ASSOCIAZIONE PRAGMA

Interview with Joseph Margolis

This is going to be an informal conversation about the history of American philosophy, about yourself in the history of American Philosophy. Basically, we have four parts of the interview. When and how you encountered pragmatism and what interested you in it, if you think there is an American tradition of philosophy, and then about yourself in this tradition. And then your view about the prospect of the future, your prophecies. It is part of your profile to have a clear view of the future, it is quite distinctive of you, as far as I can see. You are the most prophetic thinker. So, let's start from the beginning. Your recollection about what was pragmatism when you were an undergraduate and then a graduate student, what was possible to study and where, whether you encountered pragmatism at that time.

I think that I knew almost nothing about pragmatism until I went to Columbia University in 1947, if I am not mistaken. That was pretty close to Dewey's death. He lived a few years beyond that but I actually heard him lecture at Columbia on his $90^{\text {th }}$ birthday.

\section{How was the conference?}

It was good. It was completely informal. One charming thing that happened was that his wife combed his hair before he began and he had to sort of submit to this. He was very modest in a way and Columbia at that time was the center of pragmatism, I suppose, but it had already began to decline because there was a split between the so-called pragmatists and the naturalists, and the naturalists were winning.

\section{And they were opposed along this line?}

They were opposed. For example, Ernest Nagel, who was a well-known logician, was a naturalist rather than a pragmatist. I did not realize how carefully this contrast was made at that time. The naturalists made a very strong case about the primacy of science and philosophy generated from science, whereas the pragmatists were particularly committed to Dewey and tended to minimize Peirce. Which is extremely interesting: a division which from the outside one would say was nonsense, but it meant that the informality which was characteristic of Dewey was viewed as a kind of illiteracy from the point of view of the so-called naturalists who were interested in the theory of science primarily. They had no objection to the humanism of, let us say, Dewey's approach or James' approach but they were not that much interested in it except in terms of the political reality which had to do with the Second World War. 


\section{And at that time I suppose political philosophy was not a really important part of philosophy, was it?}

It was not an important part of philosophy, although Marxism was at that time stronger than at any other time. I actually went to a meeting in which a man who claimed to be something of an authority on the Marxist position gave the lead paper (I remember his name, Summerville). He was rather well-known but not a very strong figure, and his commentator was Ernest Nagel. Nagel said, I remember it to this day, after Summerville gave his account: well, since Professor Summerville hasn't told you what Marxism is, I'll begin by defining it, which he then did very well.

\section{Was naturalism at that time something related to analytic philosophy?}

Absolutely.

\section{Was it reductionist?}

It was not reductionism but it was in fact strongly committed to a naturalism of scientific orientation. Perhaps more explicitly committed to extensionalism - as far as it could be applied. I actually occupied Nagel's office one summer when I taught at Columbia, which was dominated by a huge photograph of Bertrand Russell. When I came to Columbia the semi-official commitment of the department was to pragmatism but I did not understand at the time the division. It was blunted but it created frictions inside the department, perhaps inside the New York City academy as a whole.

But that means that the classical pragmatists were taught. You could follow courses on Dewey or James.

It was declining already because in the 1940s pragmatism looked as if it was finished. But inside Columbia you would not have believed it. So when I left and started my career I discovered that almost no one in the United States was interested in pragmatism.

\section{What was the general perception about pragmatism?}

A failed program.

\section{Because philosophy was dominated by a scientific paradigm.}

Exactly. They had to answer, so to say, the influence of positivism, so they were combating reductionism on the one hand, or logicism or something of the kind, and on the other hand they were combating the perception of the weakness or isolation of pragmatism in the manner of Dewey. Even Peirce had written a letter which he 
never sent to Dewey - it is mentioned in Brent's biography - effectively: I don't think you understand negation - which pretty well sums up Peirce's estimate of Dewey's command of logic and science. It may even have been true. The Logic was widely viewed as a failed book because it tries (unsuccessfully) to reconcile standard formal logic and a kind of dynamic account of the "logic" of inquiry. The latter required an informal, instrumentalist, existential working account of "logical structure", which someone like Ernest Nagel, primarily as a logician and philosopher of science, would have found hopeless. I don't think this is the right way to read Dewey's Logic. The two principal figures of that time, Hempel and Nagel, were both drawn in somewhat different ways to the unity of science program. They were both European émigrés. Nagel was Czech; I am not sure of Hempel's origin. He was of course associated with, but was never a member of, the Vienna Circle. Similarly, Reichenbach was never a member of the Vienna Circle - I had thought he was a member but apparently not.

\section{He was a member of the Berlin Circle.}

He may have been in the Berlin Circle. I'm not sure. He was certainly in Berlin, probably at the time Carnap went to Vienna, when the two groups merged. But they were strongly committed to reductionism, extensionalism, and also (at least originally) to Carnap's failed notion of the primacy of protocol sentences. The American naturalists were opposed to reductionism and they were not persuaded that the Hempelian program (extensionalism) was satisfactory. For example, in addressing Hempel's famous essay on the role of history with regard to the laws of nature and scientific explanation, which may have became the most famous and widely debated of Hempel's papers. So, when I left Columbia, I discovered that almost no one was interested in pragmatism. I felt that I'd been misled at Columbia.

\section{But you did your Ph.D. in Columbia?}

Yes, but the facts regarding the reception of pragmatism were not generally acknowledged in a public way. They were talking as if these views dominated the professional discussion. But it wasn't true.

\section{Which was the topic of your dissertation?}

It was in moral philosophy, but I've lost track of it. It was a completely routine labor. I confess it had no relevance at all.

\section{Was it in analytic moral philosophy?}

Yes, but I didn't have sufficient analytic training of the right kind. I did read nearly all of Nagel's works. In my opinion, he was the most gifted member of the department. 


\section{So the pragmatism you had at that time was?}

It was essentially a variation of Dewey's position, very thinly presented.

\section{Essentially Dewey. Not Peirce?}

Peirce was hardly mentioned. Well there was Justus Buchler, who taught for a while, but he tended to teach (very ably) the history of philosophy. He never taught American Philosophy while he was at Columbia. And the man who taught American Philosophy, Joseph Blau, actually omitted Peirce, both in his lectures and in his book ${ }^{1}$. He never seems to have discussed Peirce, which is extremely interesting. He couldn't handle it, he wasn't up to it. He couldn't have done it. Probably it was a concession, since Buchler was still in the department. It would have been very problematic to have had whispers of an unequal presentation of Peirce. There was also a man named Herbert Schneider. He wrote an interesting, rather complicated history of American Philosophy ${ }^{2}$. I found the entire program quite unsatisfactory.

\section{Was he at Columbia too?}

He was at Columbia too. He was one of my professors.

\section{So, you were taught pragmatism and then pragmatism disappeared.}

I realized I had to master analytic philosophy in order to have my own career, so I started to instruct myself in that. I am essentially self-taught in the history of analytic philosophy, and I think I have managed, not too badly, to get a command of the entire Anglo-American tradition. So, for example, Putnam begins as a very strong unity-of-science figure, as in his first paper in the Minnesota Studies in the Philosophy of Science ${ }^{3}$. He was closely associated with Carnap, who, of course, himself took a pragmatist turn. This is another very complicated story. I came to see that Quine had really planned to undermine Carnap's program very early - when he went to Germany to work with Carnap. After his stay, he published "Two Dogmas of Empiricism"4, and, within the year, Carnap wrote a paper (never published) which appears in the collection Dear Carnap, Dear Van, in which Carnap says something to the effect that Quine and I have discussed the analytic/synthetic problem ${ }^{5}$. He's perfectly aware that it's my view that the notion of analyticity can't be properly addressed except in the setting of a highly formalized language - which Quine does not mention in the "Two

1. Blau J., (1952), Men and Movements in American Philosophy, Englewood Cliffs: Prentice-Hall.

2. Schneider H., (1946), A History of American Philosophy, New York: Columbia University Press.

3. Putnam H. and Oppenheim P., (1958), "Unity of Science as a Working Hypothesis, in Concepts, Theories, and the Mind-Body Problem", Minnesota Studies in Philosophy of Science, 2, 3-35.

4. Quine W. V. O., (1951), “Two Dogmas of Empiricism”, Philosophical Review, 60, 20-43, reprinted in From a Logical Point of View, Cambridge: Harvard University Press, 1953, 20-46.

5. Creath R., ed., (1990), Dear Carnap, Dear Van: The Quine-Carnap Correspondence and Related Work, Berkeley and Los Angeles: University of California Press. 
Dogmas" paper - certainly not in terms of naturalized language usage. Quine won the argument by changing the topic. My view is that, effectively, he won the argument as well, but the issue remains quarrelsome. This appears to have provoked Kripke to try to recover the use of the concept of necessity in the analysis of certain kind of sentences featured in Naming and Necessity ${ }^{6}$.

But at the end he undermined the analytic program even more than Quine.

Well, he undermines it, yes. And he also doesn’t defend his own views adequately.

\section{Are you mentioning this as a part of recovering pragmatism?}

In a way. When I acquired a reasonable confidence in analytic philosophy I began to realize that I was restricting myself in the same way the analytic philosophers were, and in a curious way the pragmatists had a wider scope than the so-called analytic philosophers, but there are limitations in both programs. Then I began reading socalled continental philosophy. I decided personally that I had to know the work of the principal continental figures including, say, those who favor phenomenology, which I took to be of two different forms, the Husserlian and the Heideggerian.

\section{This was quite a while after.}

Absolutely. When I did that I used to go to the meetings of the Society of Phenomenology and Existential philosophy, which is associated with the founding of the Journal [The Journal for Philosophy and Phenomenological Research]. Then I was criticized by two different populations. The analysts say "he's a traitor", and the phenomenologists said "he's on holiday".

\section{What about the pragmatists at that time?}

There weren't any. They were all hiding. They did what they did but they had no longer any force. I was in meetings where I was asked to say something about my background. When I mentioned pragmatism, nobody took it seriously.

\section{What years are those?}

Anywhere from the mid 1950s through the 1960s. 1960, if I am not mistaken, is the date of the publication of Word and Object ${ }^{7}$. That represented the new wave of analytic philosophy. The book is very ingenious: it abstracts the most important themes that could be defended without the apparatus of positivism itself: chiefly, an informal materialism and an extensionalism treated programmatically. So, I think

6. Kripke S., (1980), Naming and Necessity, Cambridge: Harvard University Press.

7. Quine W. V. O., (1960), Word and Object, Cambridge: MIT Press. 
what Quine did was to define a very modest core within the earlier tradition which could be represented as the real center of scientific philosophy, or philosophy scientifically oriented, which he hoped to salvage. On the whole, the analytic program dwindled from that time on, though many analysts thought they saw a new surge. Of course, the foundation of the surge was completely lost, which I think explains in good part Putnam's later career as a pragmatist. He kept retreating from his original commitment to the unity-of-science program. He may well be the best of the younger figures associated with the analytic tradition, now qualified along pragmatist lines, as is also true of the later work of Carnap and Quine.

Basically, I mean, you, Dick Rorty and Putnam started leaving the analytic tradition in the same years, at the end of the 1960s beginning of the 1970s. Only Rorty turned immediately to pragmatism while you were entering in a sort of continental tour.

Yes, that's right. All making excursions in different directions depending on their own history, to get some kind of larger sensibility in a way. Dick Bernstein had familiarity with Marxism, for example, and he became interested in existentialism.

\section{Dick Bernstein never was an analytic philosopher.}

In fact, he was severely criticized for that, particularly by a man I knew a little, Russell Hanson, who effectively conducted a vendetta against Bernstein. A successful one because he ousted him from the editorship of the Review of Metaphysics. I believe he made it impossible for him to remain in that position.

And at that time, although you had of course already a general knowledge of pragmatism, still you were more attracted by continental philosophy.

I began to see that I needed some continental philosophy, particularly in terms of the theory of culture, the concept of the self, the theory of history, and the bearings of all these matters, especially on epistemology. I still see the relevance. For example, I am now trying to get clear about the limitations of Brandom's so-called pragmatist maneuver. I see the issue in Brandom's inferentialism and the primacy of linguistic analysis very clearly. I am trying to write on that now, the fact that Brandom couldn't really extend the formalist program of analysis in the direction of pragmatism without attention to the underlying background questions. This is a man who has been writing on Heidegger and Hegel and, you say, well if he is doing that why isn't he continuing with the research on the background which would have put him in touch with the same sources that influenced early pragmatism. He doesn't do it, which is an interesting problem. Also a friend of Brandom's, a man I haven't met, an Australian philosopher, Huw Price, claims, not unreasonably, that Brandom is a counterrevolutionary (in his 
new book, Naturalism without Mirrors ${ }^{8}$ ). I'm inclined to say that Brandom's venture cannot but be regressive. I don't think he ever motivates his pragmatically orientated inferentialism satisfactorily. I think it cannot make sense without an adequate theory of the human self, human culture, human history and the like, and I more than doubt that it can take an algorithmic form.

He has this idea that semantics must become the prima philosophia.

Exactly. This criticism is the natural extension of what we have been talking about.

A last question about this kind of background. So, Dick Bernstein, when we talked with him, said that there was something generational about the fact that you all were philosophers in a deep sense, and he sees that there is something generational. Do you think the same?

I think that's true but I do also think two things about Dick Bernstein. One is: he was really committed to a position in terms of his reading and analysis of the early days in which philosophy favored a genuinely wider sweep of interest than pragmatism or analytic philosophy, now narrowly conceived. I think he sees himself as having been there before the rest of us finally came around to a congenial view. He was there from the beginning. He would like that to be known.

\section{He wrote a book on Dewey in $1960^{9}$ !}

Praxis and Action is, I think, his best book ${ }^{10}$.

It is a syncretistic book! Keeping together so many different cultural options.

But he also sees them as alternative directions of interest generated from the Kantian-Hegelian beginning, which is a good perception. I think it may well be true that he has very little interest in analytic philosophy.

\section{You, Rorty, and Putnam started as analytic philosophers.}

Rorty was the most extreme material reductionist, apart from Feyerabend, that one could mention at that time. So when he changed, he changed in a way that was rather baffling. I could not see his purpose at first. My own opinion is that part of his anti-philosophy is meant to be a sort of revenge against the department at Princeton,

8. Price H., (2011), Naturalism Without Mirrors, Oxford: Oxford University Press.

9. Bernstein R. J., ed., (1960), On Experience, Nature, and Freedom: Representative Selections, New York: Bobbs-Merrill.

10. Bernstein R., (1971), Praxis and Action: Contemporary Philosophies of Human Activity, Philadelphia: University of Pennsylvania Press. 
because they were super-analysts, David Lewis for example. What he really did was to forge an alliance with Donald Davidson, who is a very questionable figure in my opinion. Davidson's principal target, as I saw matters, was Quine. He was bent on undermining Quine's "less than rigorous" doctrines - and he was unable to succeed. I offer two clues. One concerns Davidson's program of radical interpretation. He claims (problematically) that Quine's doctrine of radical translation is a petitio and can only be resolved by the intended device of his own radical interpretation, which appeals to non-linguistic means; but that's impossible. It's a crazy idea, and it's ultimately regressive. The other clue comes from his theory of a conceptual scheme, which I regard as a gross misreading of Kuhn and Feyeraband. With the possible exception of Whorf, nobody ever offered a conceptual scheme which was taken to be a closed system. I mean, conceptual systems are open systems within an encompassing language. But if so, then Davidson has simply distorted an extremely important option affecting the theory of science and philosophy in general. I don't think Davidson's attack on Kuhn is tenable; I regard the argument about incommensurabilism and relativism to be well-worth pragmatism's notice. The fact is, nearly everyone - including Davidson, Putnam and Rorty - rejected all forms of relativism, although none of them paid any attention to modest forms of relativism completely compatible with stronger views about bivalent logic, and so forth. I don't know if all this makes sense in terms of your own picture of things. I began to see very early that pragmatism had never lost its best intention - largely contra Kant - namely, the import of the formation of persons, the flux of historical life, the dependence of an acceptable picture of reality in terms of the resources of historically formed human societies. I began to recover what I took to be the primacy of pragmatism itself.

\section{When was that? In the 1980s?}

Yes. I think it really came out of my following the debate between Rorty and Putnam, because each one charged the other with being a relativist. It was complete nonsense on both sides - a kind of insider quarrel that had no resolution. But the strange thing is that it generated a fresh interest in pragmatism that suddenly flowered in new directions.

Because at that time relativism was a sort of insult in the Anglo-American world. It was not an analytic concept, but an insult.

I have been criticized for this from one end of the room to the other, but now I find that there are more and more people who seek a plausible relativism that can be reconciled with bivalence. That is, a limited form of relativism.

This because of the failure of strong version of realism, so many people are just converging to the center, and in the center either you are a mild relativist or you are mild realist, which amounts basically to the same thing. 
Well, I think so. I have the idea that pluralism is not a clear category. People often construe pluralism to signify no more than making provision for a plurality of ways of proceeding. But read thus, pluralism may be no more than a form of objectivism (approached diversely). Pluralism could also be code for a viable relativism. Hence, when Putnam regards himself as a pluralist I say he is obscuring his position, he is not explaining it because he does not bring the issue to the point where he confronts the idea of there being in principle a unified theory that all the fragments of theory must converge on or where he believes there could be a fundamental incompatibility between viable competing theories fitted to the same world. Anyway, there seems to me to be an open question that very few people are paying attention to. I think that also explains the limitations of Bernstein's view because Bernstein never ventures a solution in his Beyond Objectivism and Relativism ${ }^{11}$. Putnam does not appear in it. Bernstein records the weakness of objectivism and the weakness of an intolerable relativism, but he nowhere considers the possibility of objectivity under relativistic conditions. He does not consider it at all. I regard that as an important option for an improved pragmatism.

Do you think the point of relativism is your main contribution to the pragmatist tradition? And what about aesthetics because you have worked a lot on it?

Yes, I think that my work has really come out from my notion of aesthetics. First of all, you can't do any pertinent work in the philosophy of art, history, or culture without admitting relativism. You cannot have a theory of interpretation regarding art or the rest of the cultural world of humans that does not accommodate the relativistic option.

\section{Although you reclaim the objectivity of interpretation.}

Yes, exactly, the objectivity of relativistic interpretations! It need not be the case that objectivity necessitates bivalence with respect to truth-values. A many-valued logic - accommodating "reasonable", "plausible", and the like, where bivalence doesn't suit, can be reconciled with bivalence nevertheless.

\section{It is relative to the object.}

Yes, if you concede my thesis that cultural entities have determinable semiotic properties, but are not determinate in this regard. So, there is a kind of metaphysical basis for considering relativism and reconciling it with objectivity. There is a famous instance, the much-discussed poems by William Wordsworth, the so-called "Lucy Poems", where two well-known interpretations that are absolutely opposed to one another can be shown to be validly supported by the same poem. Wordsworth himself

11. Bernstein R., (1983), Beyond Objectivism and Relativism: Science, Hermeneutics, and Praxis, Philadelphia: University of Pennsylvania Press. 
is known to have used a very lean vocabulary, so that there are usually no problems of ambiguity or equivocation in his verses that would complicate the picture. I have also used the case of Kafka's novels where much the same thing is true. Kafka uses a journalistic language which has no equivocation or ambiguity, and nevertheless you may be baffled to find the unique meaning of The Trial or The Castle. There is no single meaning, but there are many different (including incompatible) readings or interpretations.

\section{But not whatever meaning.}

Right. And so I tried to construct a theory of what it means to be a validly assigned meaning to a painting or a poem.

Would you say you were in a way forced to develop a philosophical anthropology?

Yes, all of this came out of that. The truth is that I was developing this account apart from my inquiries regarding pragmatism. I worked for quite a while chiefly in philosophy of art. It turned out that when I came to Temple, the most important member of the department was Monroe Beardsley, who was indeed the single most important figure in aesthetics in the English-speaking world. He was my colleague. So I never taught aesthetics or philosophy of art at Temple at that time, I think, until Beardsley began to ail. Our views were opposed, but we remained on friendly terms. Beardsley was a very nice man.

\section{So, you weren't teaching aesthetics.}

No, and that is one reason why I developed all these other areas because I was forced to get an education! Because of the way they all converged. They converged very naturally. I began to explore the force of this evolving unity. At about the same time, I wanted to capture the debate between Rorty and Putnam before it dissolved. So I planned three volumes: the first one was just a kind of quasi-journalistic report with associations bearing on the import of the debate between Rorty and Putnam ${ }^{12}$. The second was a broadside against analytic scientism ${ }^{13}$. The third volume began to formulate what I saw was the "advantage" of pragmatism in the setting of Eurocentric philosophy ${ }^{14}$.

12. Margolis J., (2007, 2d ed.), Pragmatism without Foundations: Reconciling Realism and Relativism, New York: Continuum.

13. Margolis J., (2003), The Unraveling of Scientism: American Philosophy at the End of the Twentieth Century, Itahca: Cornell University Press. See also Margolis J., (2002), Reinventing Pragmatism: American Philosophy at the End of the Twentieth Century, Ithaca: Cornell University Press.

14. Margolis J., (2010), Pragmatism's Advantage. American And European Philosophy at the End of the Twentieth Century, Stanford: Stanford University Press. 


\section{The Unraveling of Scientism.}

That's right. It was part of the same effort. To my mind, I began collecting the whole tradition of Anglo-American philosophy seen from a pragmatist point of view. And then the third and fourth volumes (of the series) followed suit ${ }^{15}$. I began to see that I would have to take account of important continental themes and reinterpret what I took to be the generating theme of the Kantian-Hegelian revolution. That is precisely what happened (the issues of the last two books of the series). In the meanwhile, I realized that I needed to begin an entirely new series centered on the themes, collected from the side of the theory of culture, namely, the theory of the human self, the theory of human society, language and history. And now the first one of that series is fully drafted. It's centered on my analysis of the human person influenced by Darwinian and post-Darwinian studies - and so fits both my work in pragmatism and the philosophy of art.

\section{This is the naturalistic theme that encompasses all your work.}

Yes, it is quintessentially naturalistic. The interesting thing is that naturalists have never discussed these issues in a sustained way. I mean, American naturalists; the Europeans have a rich discussion of the pertinent issues. I followed the so-called German philosophical anthropologists, Max Scheler, Helmuth Plessner and Arnold Gehlen, who is the youngest of this group, and the zoologist, Adolf Portmann. The American pragmatists have neglected these themes and figures. I have done rather a lot of work now on the higher primates and the paleoanthropological record and have a particular interest in the bonobos. The most important finding that I dare claim any right to centers on the thesis that the human self is a hybrid cultural artifact.

Let me come back for a while on this. It is quite clear that you came out of analytic philosophy for a sort of dissatisfaction with its too restricted way of understanding human life. So you were looking for a better understanding of culture and society, and you entered into a discovery of continental philosophy. But which were the reasons of such dissatisfaction that made you to try to sort out of analytic philosophy and rediscover pragmatism?

I think that perhaps the key theme is history or historicity itself. That is the idea that thinking and understanding change over historical time. Of course it has a continuum of some sort: children understand their parents, but they always have a sense that they are not thinking in quite the same way we think. Everyone has that sense, which keeps accelerating because of technology. And then I began to see that all this obviously depended on our view of language and of the formation of the self as being capable of all the characteristic things that we do. Now, there is an interesting point in Huw

15. The forth volume is Margolis J., (2012), Pragmatism Ascendent. A Yard of Narrative, a Touch of Prophecy, Stanford: Stanford University Press. 
Price's paper in which - although he clearly has affection for Brandom, he is still criticizing him - he formulates his theory of naturalism. Maybe in the naturalism paper which appeared in the collection De Caro and MacArthur edited ${ }^{16}$. In that paper he makes it very clear that what he calls object naturalism presupposes subject naturalism, and subject naturalism concerns our grasp of the natural standing of the capacities of human intelligence and understanding or inquiry. Price does not answer the question, but he is very frank to say that he's not entirely clear that anyone has been able to show that this can be put naturalistically. He raises the question.

How is this related to your transition from Continental philosophy to pragmatism?

I do not know that I have made a transition. It is not a question of moving from one to another philosophical program or vision. It's more a matter of building an ampler account in which all of these elements have a place. Someone said to me yesterday: why don't we pragmatists invent a new term for what we are doing? My best shot, which I would say is a bad one but which captures what I think is close to the core of pragmatism, is based on Peirce's distinction between cable and chain: call it philosophical cablism!

It is funny that within the pragmatist tradition people start thinking about changing name in the very precise moment in history when pragmatism is becoming a trendy label, because everybody is pragmatist now.

It is a PR idea!

Huw Price is founding the Cambridge pragmatist group, but Cambridge in the UK. And he is reclaiming Elizabeth Anscombe as the founding father of the pragmatism.

Well, Brandom says in his little book Articulating Reasons that Frege is a pragmatist $^{17}$.

The last question is about your prophecies for the future. I think one important point you made is pragmatism to become a philosophy for the future, we should stop looking backwards too much, we should stop considering Dewey and Peirce and James as they were completely true. Their theories were mistaken, much in a way as Heidegger's theory was, for instance.

16. Price H., (2004), "Naturalism without Representationalism", in M. De Caro, and D. MacArthur (eds.), Naturalism in Question, Cambridge: Harvard University Press, 71-88, reprinted in Price, Naturalism without Mirrors, 184-199.

17. Brandom R., (2000), Articulating Reasons: An Introduction to Inferentialism, Cambdrige: Harvard University Press. 
I think what Dewey came closest to capturing is what I have called the doctrine of the flux, the changeability of the world. That is the clue to instrumentalism in his sense. So he was uneasy about the fixity of metaphysical categories, but he could not find an idiom for replacing what looks like the fixity of substance and attributes. I do not myself see that it is that difficult: we can take the old vocabulary and treat it in a fluxive way. You can make provisional identifications of your referent and make predications of it as before because that seems congenial to a certain practical effectiveness. I think Dewey saw a difficulty which does not seem to me to be there. I think that Experience and Nature shows that he worked with a conventional vocabulary although he signaled his own sense of how to proceed: we should not proceed in an essentialist way or in a related way ${ }^{18}$. So, I think he laid the ground for that sort of resistance. I personally believe the most important category is the artifactuality of the human self; hence, that the rigor of language, the normativity of discourse, is artifactual as well. Morality does not have a natural basis, I would say, in that sense; but there are natural considerations in virtue of which we construct one or another morality. So constructivism is the consequence of the artifactuality of the human self. We construct methodologies for science and codes of conduct for human beings under changing conditions. Why not? I mean, the very idea that whatever the herders and farmers of the ancient world thought was morally reasonable should be timelessly true today seems to me completely contrary to our usual reflections on the history of the race. So, the artifactuality of the self, the constructive nature of the historical world (not the physical world), the historicity of the forms of life which follow from this, and therefore the possibility of relativism, historicism, the pluralistic diversity of thought and experience plus the fact that no philosophical movement is sufficiently strong by itself - strong enough to address all pertinent questions without the resources of other parts of genuinely Eurocentric culture that it has no inkling of. If I were younger I would add Asian thought to our intellectual needs.

The important thing is that when you reclaim what you call Eurocentric philosophy, and when you say that pragmatism is synthesizing all these, you are not saying that James Dewey and Peirce make the synthesis of European philosophy. You are saying that from this platform we are opening to something new. For which we have a European motto: Hegelianizing Darwin and Darwinizing Hegel, which is a European motto pronounced by an American philosopher.

Of course, you're entirely right.

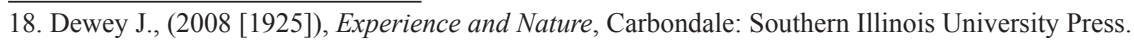

